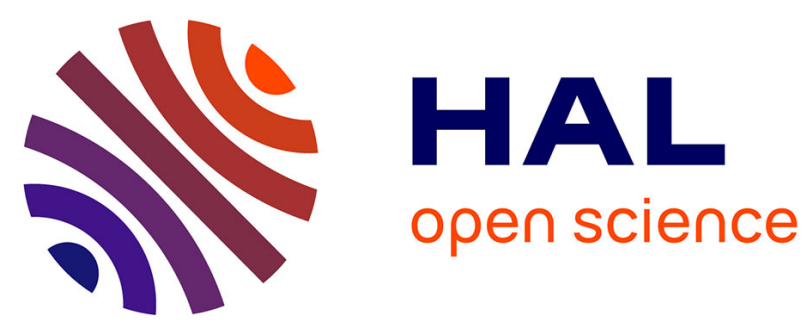

\title{
Densification and polymorphic transition of multiphase Y2O3 nanoparticles during spark plasma sintering
}

\author{
Rachel Marder, Rachman Chaim, Geoffroy Chevallier, Claude Estournès
}

\section{To cite this version:}

Rachel Marder, Rachman Chaim, Geoffroy Chevallier, Claude Estournès. Densification and polymorphic transition of multiphase Y2O3 nanoparticles during spark plasma sintering. Materials Science and Engineering: A, 2011, vol.528, pp. 7200-7206. 10.1016/j.msea.2011.06.044 . hal-00720725

\section{HAL Id: hal-00720725 \\ https://hal.science/hal-00720725}

Submitted on 25 Jul 2012

HAL is a multi-disciplinary open access archive for the deposit and dissemination of scientific research documents, whether they are published or not. The documents may come from teaching and research institutions in France or abroad, or from public or private research centers.
L'archive ouverte pluridisciplinaire HAL, est destinée au dépôt et à la diffusion de documents scientifiques de niveau recherche, publiés ou non, émanant des établissements d'enseignement et de recherche français ou étrangers, des laboratoires publics ou privés. 


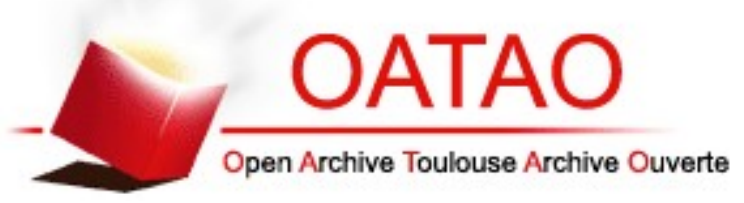

\section{Open Archive Toulouse Archive Ouverte (OATAO)}

OATAO is an open access repository that collects the work of Toulouse researchers and makes it freely available over the web where possible.

This is an author-deposited version published in: http://oatao.univ-toulouse.fr/ Eprints ID: 5668

To link to this article: DOI: $10.1016 /$ j.msea.2011.06.044

URL : ttp://dx.doi.org/10.1016/j.msea.2011.06.044

\section{To cite this version:}

Marder, Rachel and Chaim , Rachman and Chevallier, Geoffroy and Estournès, Claude Densification and polymorphic transition of multiphase Y2O3 nanoparticles during spark plasma sintering. (2011) Materials Science and Engineering A, vol.528 ( $\mathrm{n}^{\circ}$ 24). pp. 7200-7206. ISSN 09215093

Any correspondence concerning this service should be sent to the repository administrator: staff-oatao@listes.diff.inp-toulouse.fr 


\title{
Densification and polymorphic transition of multiphase $\mathrm{Y}_{2} \mathrm{O}_{3}$ nanoparticles during spark plasma sintering
}

\author{
R. Marder ${ }^{\mathrm{a}}$, R. Chaim ${ }^{\mathrm{a}, *}$, G. Chevallier ${ }^{\mathrm{b}}$, C. Estournes $^{\mathrm{b}}$ \\ a Department of Materials Engineering, Technion - Israel Institute of Technology, Haifa 32000 Israel \\ ${ }^{\mathrm{b}}$ CNRS, Institut Carnot Cirimat, F-31602 Toulouse Cedex 9, France
}

\section{Keywords:}

Spark plasma sintering

Phase transformation

Densification

$\mathrm{Y}_{2} \mathrm{O}_{3}$

\begin{abstract}
A B S T R A C T
Multiphase (MP) monoclinic and cubic $\mathrm{Y}_{2} \mathrm{O}_{3}$ nanoparticles, $40 \mathrm{~nm}$ in diameter, were densified by spark plasma sintering for $5-15 \mathrm{~min}$ and $100 \mathrm{MPa}$ at $1000^{\circ} \mathrm{C}, 1100^{\circ} \mathrm{C}$, and $1500^{\circ} \mathrm{C}$. Densification started with pressure increase at room temperature. Densification stagnated during heating compared to the high shrinkage rate in cubic single-phase reference nanopowder. The limited densification of the MP nanopowder originated from the vermicular structure (skeleton) formed during the heating. Interface controlled monoclinic to cubic polymorphic transformation above $980^{\circ} \mathrm{C}$ led to the formation of large spherical cubic grains within the vermicular matrix. This resulted in the loss of the nanocrystalline character and low final density.
\end{abstract}

\section{Introduction}

Rapid sintering and densification of ceramic powders to full density are nowadays a routine procedure, using the spark plasma sintering (SPS) method. As was noted in many hot-press studies including SPS, the main densification shrinkage of the powder aggregate takes place during the heating by particle sliding, to the close-packed arrangement [1-4]. Further densification of the powder compact may be accomplished either by plastic deformation or by diffusional processes, at the particle necks. Nevertheless, diffusional processes are inevitable during the final stage sintering, when isolated pores form and can be eliminated via bulk or grain boundary diffusion $[5,6]$. Consequently, microstructure evolution during the SPS process, due to the change in the process parameters, such as temperature, pressure, time, atmosphere, vacuum level, etc. may affect the densification mechanism. Many types of phase transformations and transitions associated with crystal symmetry changes involve changes in the microstructure and morphology [7]. Therefore, effects of the phase transformations during the densification by SPS may be of prime importance to the densification process, as well as to the final phase assemblage in the dense compact. The phase content and assemblage often have a considerable impact on the final properties of the sintered ceramic [8]. In this respect, Takeuchi et al. [9] investigated the densification of

\footnotetext{
* Corresponding author. Tel.: +972 4829 4589; fax: +972 48295677 E-mail address: rchaim@technion.ac.il (R. Chaim).
}

submicrometer size tetragonal $\mathrm{BaTiO}_{3}$ powders and found SPS to be effective for preservation of the submicrometer size metastable cubic $\mathrm{BaTiO}_{3}$ at room temperature. The preserved nanometric grain size by SPS was also found to be a cause for the cubic phase stabilization at lower temperatures $[10,11]$.

Kumar et al. [12] took advantage of the higher atomic mobility near the Anatase to Rutile phase transformation temperature to enhance the densification of the $\mathrm{TiO}_{2}$ nanoparticles. SPS of multiphase $\mathrm{TiO}_{2}$ (70\% Anatase and 30\% Rutile) with 20-nm particle size at $62 \mathrm{MPa}$ for $5 \mathrm{~min}$ and $600^{\circ} \mathrm{C}$ resulted in complete phase transformation to Rutile [13]. For comparison, only annealing of the same precursor powder for $5 \mathrm{~min}$ at $600^{\circ} \mathrm{C}$ preserved the multiphase character of the powder. This exhibits the effect of the applied pressure and possibly the electric field on the phase transformation during the SPS. Fundamental investigation of the current effect on solid-state reactivity during SPS was performed on stacked Mo-Si-Mo layers [14]. No change in the reaction mechanism was observed, albeit the enhanced growth rate of the reaction product layer $\left(\mathrm{MoSi}_{2}\right)$, which was related to the enhanced mobility or the change in the defect concentration.

The present paper focuses on the effect of the polymorphic phase transition on the microstructure and densification behavior of multiphase $\mathrm{Y}_{2} \mathrm{O}_{3}$ nanoparticles during the SPS.

\section{Experimental}

Commercial pure (99\%) multiphase (MP) $\mathrm{Y}_{2} \mathrm{O}_{3}$ nanopowder (Neomat Co., Riga, Latvia) with average particle diameter of $40 \mathrm{~nm}$ 


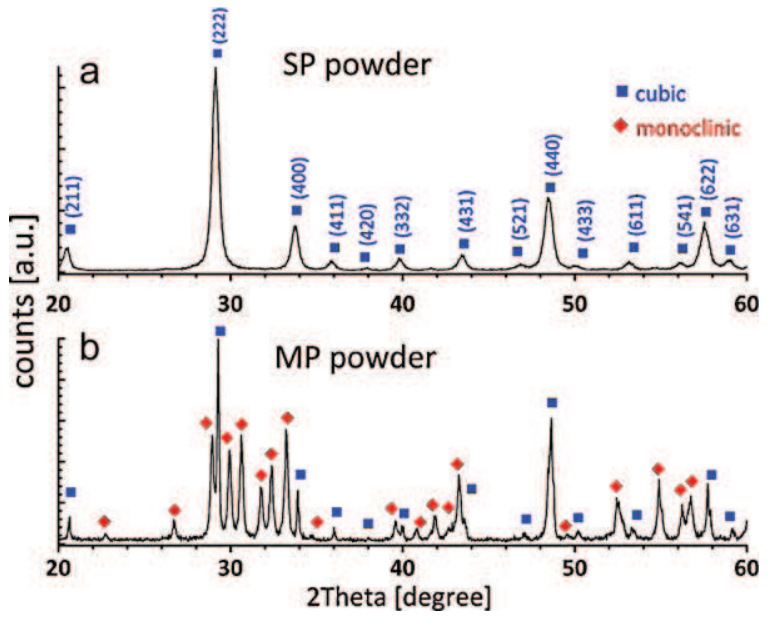

Fig. 1. X-ray diffraction spectra from the $\mathrm{Y}_{2} \mathrm{O}_{3}$ nanoparticles. (a) Single phase (SP) cubic. (b) Multiphase (MP) cubic + monoclinic.

was used. A second highly pure (99.99\%) nc- $\mathrm{Y}_{2} \mathrm{O}_{3}$ powder (Cathay Advanced Materials, China) with $100 \%$ cubic phase, designated as single phase (SP), was also used as a reference specimen [15]. Constant amount of the powder sample was poured into the graphite die using graphite foils (Grafoil) to separate between the powder, the die walls and the plunger surfaces. The powders were sintered (Dr. Sinter, SPS 2080) at different conditions for 5-15 min and $100 \mathrm{MPa}$ at $1000^{\circ} \mathrm{C}, 1100^{\circ} \mathrm{C}$, and $1500^{\circ} \mathrm{C}$. The starting temperature was room temperature for the $1000^{\circ} \mathrm{C}$ treatment (designated 'cold compaction'), but $600^{\circ} \mathrm{C}$ for the $1100^{\circ} \mathrm{C}$ and $1500^{\circ} \mathrm{C}$ treatments (designated 'hot compaction'). The uniaxial pressure was applied either a few second after the process started or when the SPS temperature was reached. In both cases, the pressure was increased linearly with time, and held constant during the isothermal treatment at the SPS temperature. The process duration refers to the isothermal SPS treatment. A heating rate of $100^{\circ} \mathrm{C} / \mathrm{min}$ and vacuum level of 3 Pa has been used; the pulse duration was $3.3 \mathrm{~ms}$. The SPS parameters were recorded during the process. The temperature was controlled by a thermocouple for 'cold compaction', while an optical pyrometer was used above $600^{\circ} \mathrm{C}$ for 'hot compaction' and at higher temperatures. The final specimen dimensions were $8 \mathrm{~mm}$ in diameter and $1.7-2.5 \mathrm{~mm}$ thick. The ram displacements were expressed in terms of the linear shrinkage and the temporary relative density, following the specimen thickness versus time, taking into account the thermal expansion/shrinkage behavior of the specimen and the graphite plungers [15].

The phase content of the as-received nano-powders and the sintered specimens were characterized by X-ray diffraction using a diffractometer (Philips PW 3710) with monochromatic $\mathrm{Cu} \mathrm{K}_{\alpha}$ radiation (XRD), operated at $40 \mathrm{kV}$ and $30 \mathrm{~mA}$. A scanning speed of $0.5^{\circ} / \mathrm{min}$ has been used. The microstructures were characterized using transmission (TEM, FEI Tecnai G2 T20, operated at $200 \mathrm{kV}$ ) and scanning (FEI E-SEM Quanta 200, operated at $20 \mathrm{kV}$ ) electron microscopes. The specimens for the electron microscopy observations were prepared by the conventional methods. The thermal stability of the nanopowders was characterized using differential scanning calorimetry (Labsys 1600 , Setaram) up to $1400^{\circ} \mathrm{C}$ in Argon atmosphere, at a heating rate of $5^{\circ} \mathrm{C} / \mathrm{min}$. The final density of the specimens was determined by the Archimedes method following ASTM standard C 20-92 ( $\pm 0.5 \%$ accuracy).

\section{Results}

$\mathrm{X}$-ray diffraction spectra from the as-received nanopowders are shown in Fig. 1. The single phase (SP) $\mathrm{Y}_{2} \mathrm{O}_{3}$ nanopowder with cubic symmetry (JCPDS 41-1105) was characterized in detail elsewhere [16] (Fig. 1a), whereas the multiphase (MP) nanopowder revealed polymorphs with cubic and monoclinic (JCPDS 39-1063) symmetries (Fig. 1b). Quantitative analysis of the spectrum in Fig. 1b, assuming a powder mixture [17], resulted in 30\% cubic and $70 \%$ monoclinic phase in the nanopowder. These results were in agreement with the 25:75 cubic to monoclinic phase ratio determined by others [18].

TEM observation of the two powders (not shown here) exhibited spherical morphology for the multiphase powder, compared to the equiaxed polyhedral shape for the cubic, single phase powder [16]. Both powders exhibited log-normal grain size distributions, with average grain size of $18 \pm 8 \mathrm{~nm}$ and $41 \pm 22 \mathrm{~nm}$ for the single phase and the multiphase powders, respectively.

XRD spectra from the MP nanopowder compacts, subjected to SPS for $5 \mathrm{~min}$ at $100 \mathrm{MPa}$ and at different temperatures (Fig. 2a), showed the transformation of the metastable monoclinic polymorph to the stable cubic phase to occur at $1100^{\circ} \mathrm{C}$. However, further XRD characterization of the MP nanopowders sintered for different durations at $1000^{\circ} \mathrm{C}$ and $100 \mathrm{MPa}$ (Fig. 2b) revealed the continuous nature of the phase transformation kinetics already at this temperature. The monoclinic to cubic polymorphic phase transformation was not completed, even after 15 min SPS duration.

Following the above phase transformation in the sintered specimens, the thermal stability of both nanopowders were characterized by DSC (Fig. 3). At the stage where the finer, cubic SP nanopowder was relatively stable, the corresponding curve from
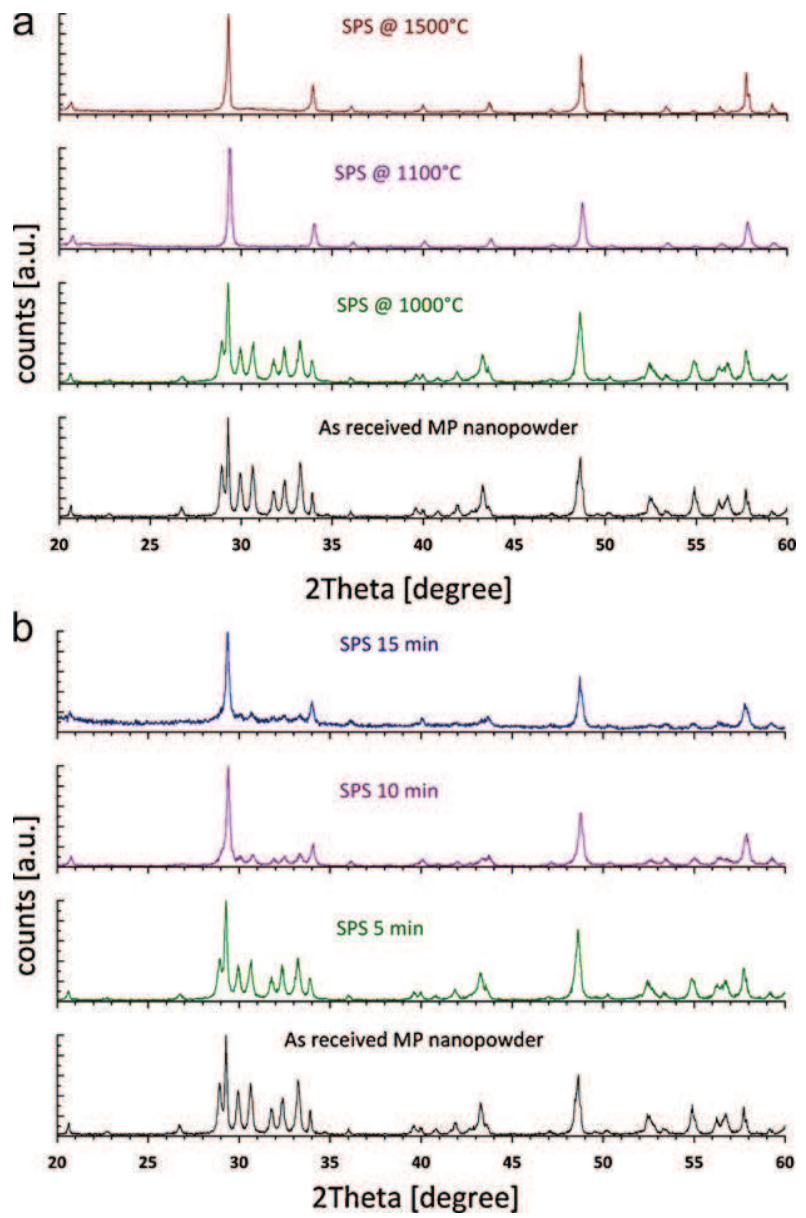

Fig. 2. XRD spectra of the as-received $\mathrm{MP}_{2} \mathrm{O}_{3}$ nanoparticles, after sintering (a) for $5 \mathrm{~min}$ at $1000^{\circ} \mathrm{C}, 1100^{\circ} \mathrm{C}$, and $1500^{\circ} \mathrm{C}$. (b) At $1000^{\circ} \mathrm{C}$ for 5,10 , and $15 \mathrm{~min}$. 


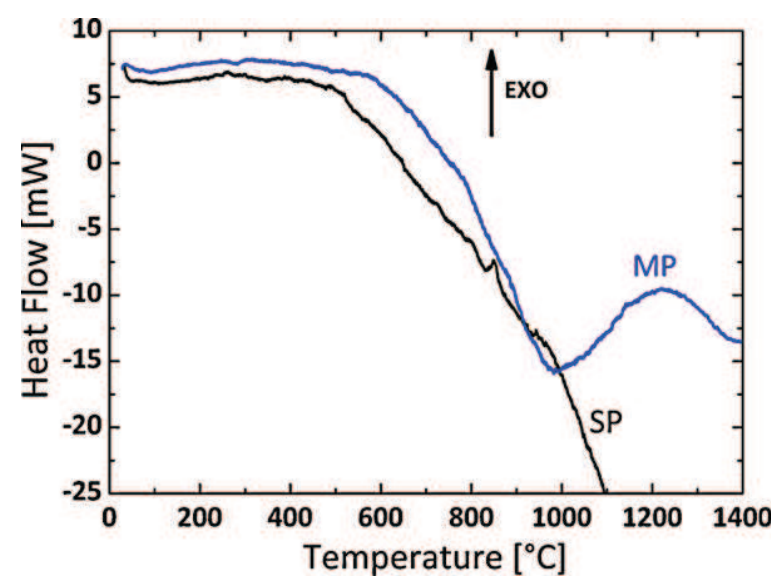

Fig. 3. Differential scanning calorimetry from nanocrystalline $\mathrm{Y}_{2} \mathrm{O}_{3}$. (a) Single phase (SP) cubic. (b) Multiphase (MP) cubic + monoclinic.

the MP nanopowder exhibited a strong exothermic peak starting at $\sim 980^{\circ} \mathrm{C}$, with the maximum around $1200^{\circ} \mathrm{C}$. This is in agreement with the expected monoclinic to cubic phase transformation reported at $\sim 950^{\circ} \mathrm{C}$ [19], and in agreement with the XRD results. Therefore, special attention was paid to this phase transformation during the densification by SPS.

Following the densification behavior of the two nano-powders, several important features were observed. First, a very rapid compaction of the MP powder was directly associated with the pressure when applied at room temperature (Fig. 4a); this room temperature compaction with the pressure increase persisted for all SPS temperatures investigated. However, further densification at elevated temperatures depended on the final SPS temperature. In the $1000^{\circ} \mathrm{C}$ 'cold compaction' treatment (Fig. 4a), the density increased
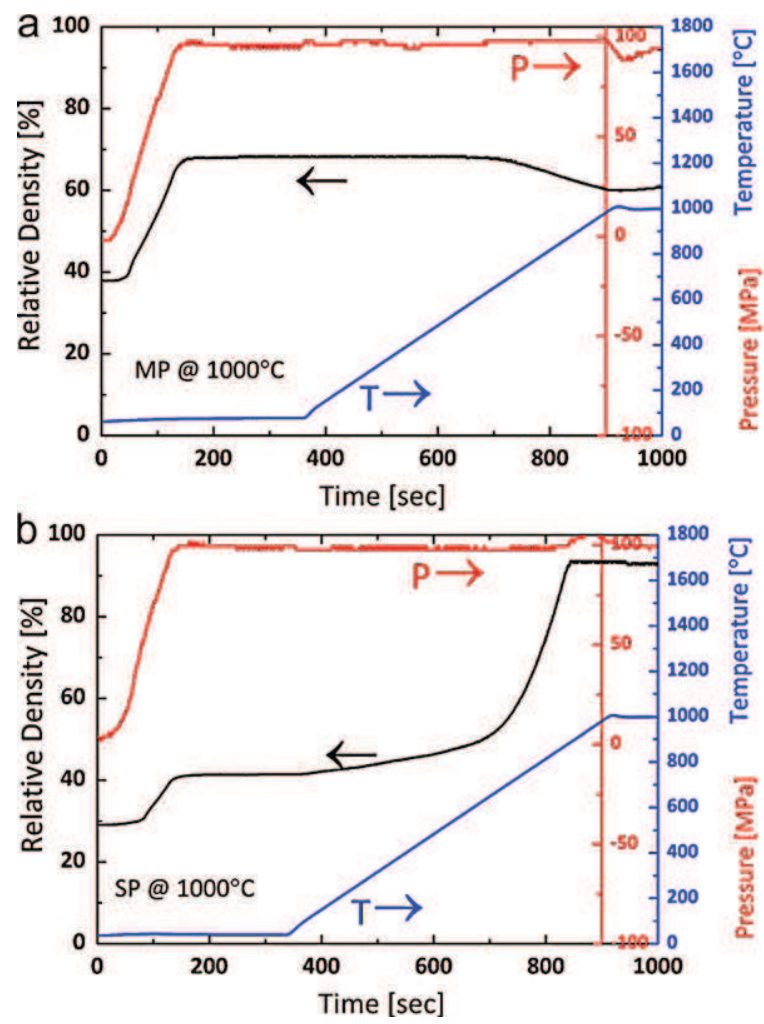

Fig. 4. Relative density-time-temperature-pressure dependencies during SPS of (a) $\mathrm{MP}$ and (b) $\mathrm{SP}_{2} \mathrm{O}_{3}$ nanoparticles at $1000{ }^{\circ} \mathrm{C}$ for $5 \mathrm{~min}$ and $100 \mathrm{MPa}$. simultaneously with the pressure increase from room temperature (i.e. SPS starting time), and leveled at $67 \%$ within 2 min,when the pressure reached its maximum value ( $100 \mathrm{MPa})$. Since the temperature was increased only after 5 min from the SPS start (Fig. 4a), the observed densification at room temperature can be related to particle sliding with negligible contribution from the diffusional processes. However, negative ram displacement was recorded at $\sim 600^{\circ} \mathrm{C}$ during heating at a constant pressure. This displacement could be associated with a certain decrease in density, but as it is ceased when the SPS temperature of $1000^{\circ} \mathrm{C}$ was reached, it can be related to the thermal expansion mismatches between that of the graphite plungers and the close packed nano-particle network. Apparently, the close packed nano-particles undergo surface diffusion during the heating to form a rigid skeleton. In such a case, the rigid skeleton may oppose further shrinkage under the constant pressure; if the thermal expansion of this skeleton is higher than that of the graphite plunger, negative ram displacement may occur. (Negative displacement due to thermal expansion of the graphite mold, plungers and spacers is usually observed with the increasing temperature using blank specimens.) This aspect will be discussed later in detail. The density did not change significantly during the SPS isotherm. In addition, increase in the SPS duration to 10 and 15 min resulted in higher densities of 74.6 and $76.0 \%$, respectively.

Densification of the $\mathrm{SP}$ reference $\mathrm{Y}_{2} \mathrm{O}_{3}$ nanopowder was recently investigated in detail under similar SPS conditions [20]. Some of the results will be used here for comparison. The density of the SP reference specimen at $1000^{\circ} \mathrm{C}$ treatment increased with the pressure increase at room temperature (Fig. 4b), although it leveled off at a much lower density of $42 \%$. However, in contrast to the MP nano-powder, further increase in the density was observed during the heating process. Densification was accelerated around $\sim 680^{\circ} \mathrm{C}$ and reached its maximum value of $93 \%$ around $\sim 880^{\circ} \mathrm{C}$, before the final SPS temperature of $1000^{\circ} \mathrm{C}$ was reached.

The heating rate to the SPS temperature of $1100^{\circ} \mathrm{C}$ was of 'hot compaction' and differed from that at $1000^{\circ} \mathrm{C}$. In this respect, a heating pulse was used to reach $600^{\circ} \mathrm{C}$ within 3 min under the holding pressure of $2 \mathrm{MPa}$ (Fig. 5a). This was followed by heating to $1100^{\circ} \mathrm{C}$ for additional $5 \mathrm{~min}$. Then the pressure was linearly increased to $100 \mathrm{MPa}$, resulting in simultaneous increase in the density to its final value of $66 \%$; no further densification was observed at the SPS isotherm. Similar densities (i.e. 63.4 and 62.8\%) were reached with further increase of the SPS duration to 10 and $15 \mathrm{~min}$, respectively. Comparison between the densities measured at two SPS regimes, i.e. at $1000^{\circ} \mathrm{C}$ and $1100^{\circ} \mathrm{C}$, revealed that the application of pressure at the beginning ('cold compaction') resulted in higher densities.

The corresponding SP specimen exhibited significant increase in the density during the heating process between $800^{\circ} \mathrm{C}$ and $\sim 1050^{\circ} \mathrm{C}$, under the $2 \mathrm{MPa}$ holding pressure only (Fig. 5b) [20]. The maximum displacement/(shrinkage) rate was $10^{-2} \mathrm{~mm} \mathrm{~s}^{-1}$. This indicated the high capillary forces in the SP to drive densification, in contrast to the MP powder, where no densification was recorded during the heating up. A higher densification rate $\left(1.5 \times 10^{-2} \mathrm{~mm} \mathrm{~s}^{-1}\right)$ was measured when the pressure was increased to its maximum value. A final density of $93 \%$, which is higher than that of the MP specimen, was reached.

The densification behavior in the MP specimen at $1500^{\circ} \mathrm{C}$ is shown in Fig. 6, as in the other experiments, a very fast densification rate $\left(1.5 \times 10^{-2} \mathrm{~mm} \mathrm{~s}^{-1}\right)$ was recorded simultaneously with the pressure increase. However, in this 'hot compaction' experiment (i.e., a heating pulse to $600^{\circ} \mathrm{C}$ was applied before the pressure was increased), densification ceased when the maximum pressure was reached. Density was stagnated during further heating up to $1350^{\circ} \mathrm{C}$, where an additional rapid densification rate $\left(5 \times 10^{-3} \mathrm{~mm} \mathrm{~s}^{-1}\right)$ up to the final density was recorded. During 

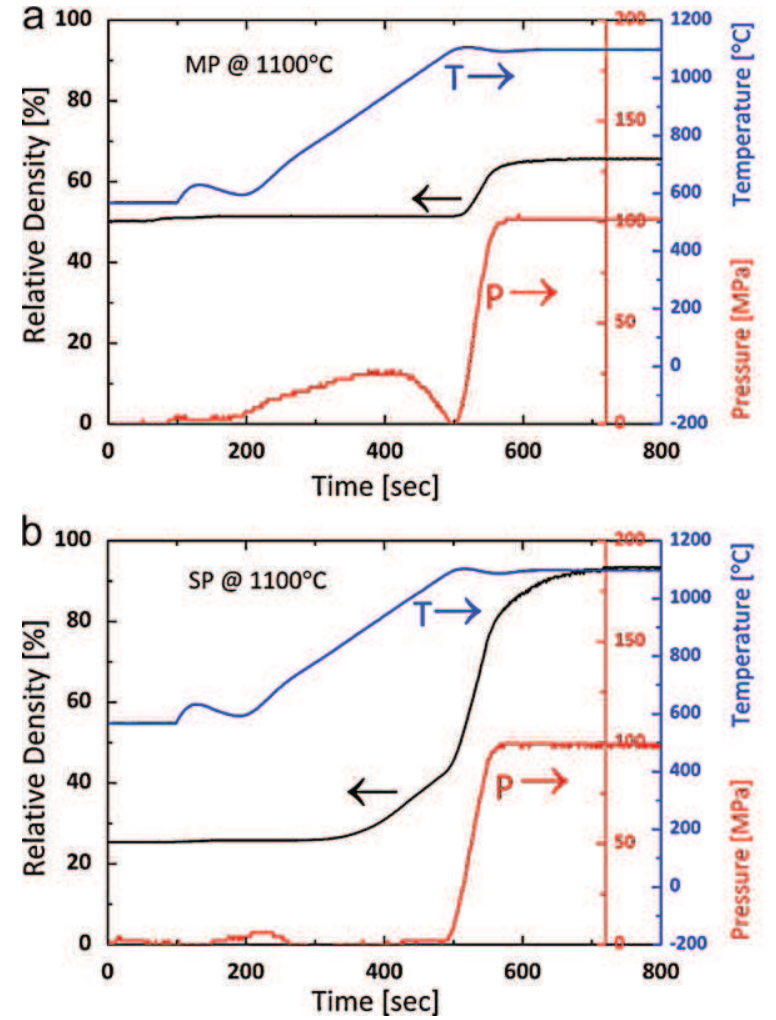

Fig. 5. Relative density-time-temperature-pressure dependencies during SPS of (a) MP and (b) $\mathrm{SP}_{2} \mathrm{O}_{3}$ nanoparticles at $1100{ }^{\circ} \mathrm{C}$ for $5 \mathrm{~min}$ and $100 \mathrm{MPa}$.

the period of density stagnation (i.e., between 200 and $650 \mathrm{~s}$ in Fig. 6), the pressure experienced two disturbances expressed by a decrease of 8-10 MPa in the recorded pressure. These decreases in pressure occurred around $1030^{\circ} \mathrm{C}$ and $1280^{\circ} \mathrm{C}$, and were recovered at $1130^{\circ} \mathrm{C}$ and $1350^{\circ} \mathrm{C}$, respectively. The second pressure recovery (increase) was responsible for the repeated increase in densification at $1350^{\circ} \mathrm{C}$, as was mentioned above. These pressure disturbances are associated with increase in the resistance of the nano-particles to undergo sliding, whether due to the formation of a rigid skeleton or jamming of the agglomerated nano-particles. In either case, thermal expansions of both the graphite plungers and the specimen together with the lack of plasticity in the specimen, introduce internal compressive stresses. Since the external pressure applied in the system is regulated to remain constant, its actual value should decrease in order to balance the internal

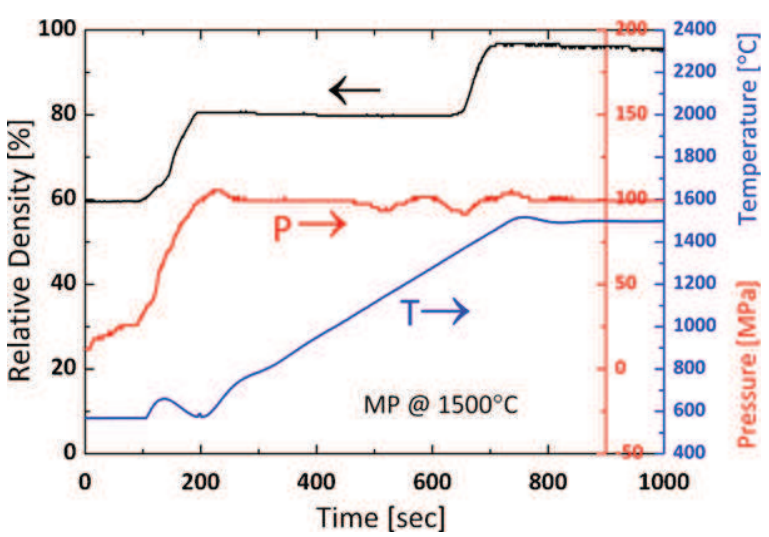

Fig. 6. Relative density-time-temperature-pressure dependencies during SPS of $\mathrm{MP}$ cubic $\mathrm{Y}_{2} \mathrm{O}_{3}$ nanoparticles at $1500^{\circ} \mathrm{C}$ for $5 \mathrm{~min}$ and $100 \mathrm{MPa}$.

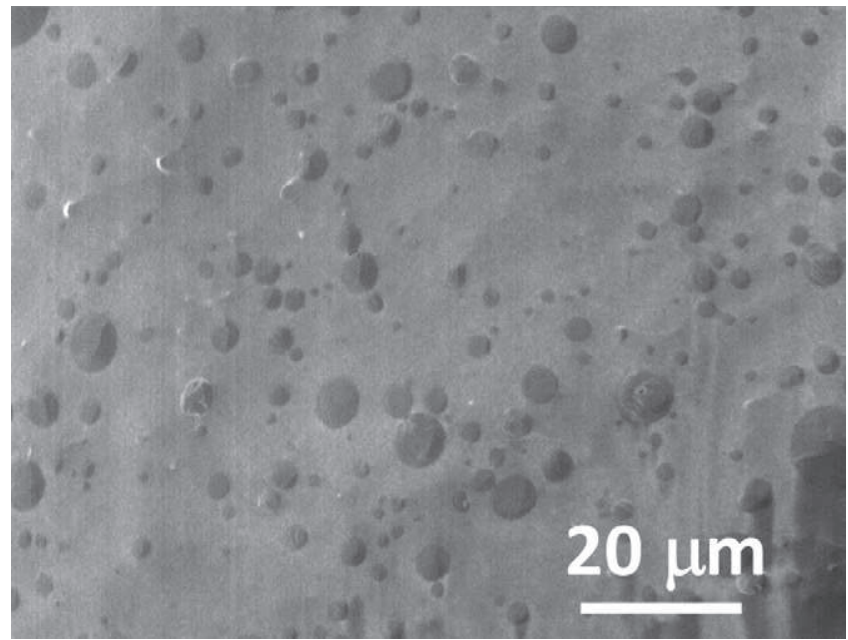

Fig. 7. SEM image showing the homogeneous distribution of the spherical grains throughout the specimen sintered at $1100^{\circ} \mathrm{C}$ for $5 \mathrm{~min}$ and $100 \mathrm{MPa}$ using multiphase $\mathrm{Y}_{2} \mathrm{O}_{3}$ nanoparticles.

thermal pressures formed. This may lead to the disturbances and decreases observed in the present SPS experiments.

SEM images from the specimens sintered at $1100^{\circ} \mathrm{C}$ for different durations (i.e. 5 min, Fig. 7) showed homogeneous distribution of many spherical shape grains throughout the matrix of the MP $\mathrm{Y}_{2} \mathrm{O}_{3}$ nanoparticles. The largest diameter of the spherical grains was $\sim 15 \mu \mathrm{m}$ after $5 \mathrm{~min}$, and $\sim 60 \mu \mathrm{m}$ after $10 \mathrm{~min}$ durations, with very wide grain size distributions. These spherical grains exhibited a low volume fraction of the specimens even after 15 min of sintering at $1100^{\circ} \mathrm{C}$. These spherical grains were absent after sintering at $1500^{\circ} \mathrm{C}$; a regular polyhedral shape grain microstructure was observed.

TEM images from the specimens sintered at different temperatures clearly revealed the microstructure evolution during the SPS. First, at $1000^{\circ} \mathrm{C}$ and $1100^{\circ} \mathrm{C}$, close to the phase transformation temperature, many polycrystalline spherical particles of submicrometer and micrometer-size in diameter were observed within the porous nanoparticle matrix (Fig. 8a). Higher magnification proved the internal structure of the large particles (Fig. 8b and c) to be composed of sub-grains separated by dislocation networks; in some occasions, internal submicrometer-size pores were also observed. The matrix was comprised of partially sintered nanoparticles which formed a porous network resembling the vermicular structure (the upper part in Fig. 8b). Detailed examination of the interface between the spherical particles and the vermicular structure revealed that the former grow on the account of the porous nanoparticle skeleton (Fig. 8c). Selected area diffraction patterns confirmed the cubic crystal symmetry of the spherical particles (Fig. 8d). Therefore, it seems that the spherical particles present nucleation and interface-controlled growth of the cubic grains on the account of the monoclinic nanoparticles.

Finally, TEM images from the $1500^{\circ} \mathrm{C}$ treated specimen, shown in Fig. 9, exhibit the micrometer size polyhedral shape grains with nanometric closed pores. Many grains were comprised of sub-grains separated by dislocation networks (Fig. 9b). A few nanometer size grains and closed pores were still visible along the sub-grain boundaries and at their corners (arrowed in Fig. 9b). This microstructure can be considered as an almost fully transformed version of the vermicular structure to the cubic grains. The microstructure evolution in the reference single-phase cubic nanoparticle compacts during the SPS were described in detail elsewhere $[15,16,20]$. At SPS temperatures below $1100^{\circ} \mathrm{C}$, the nanometric character of the dense 

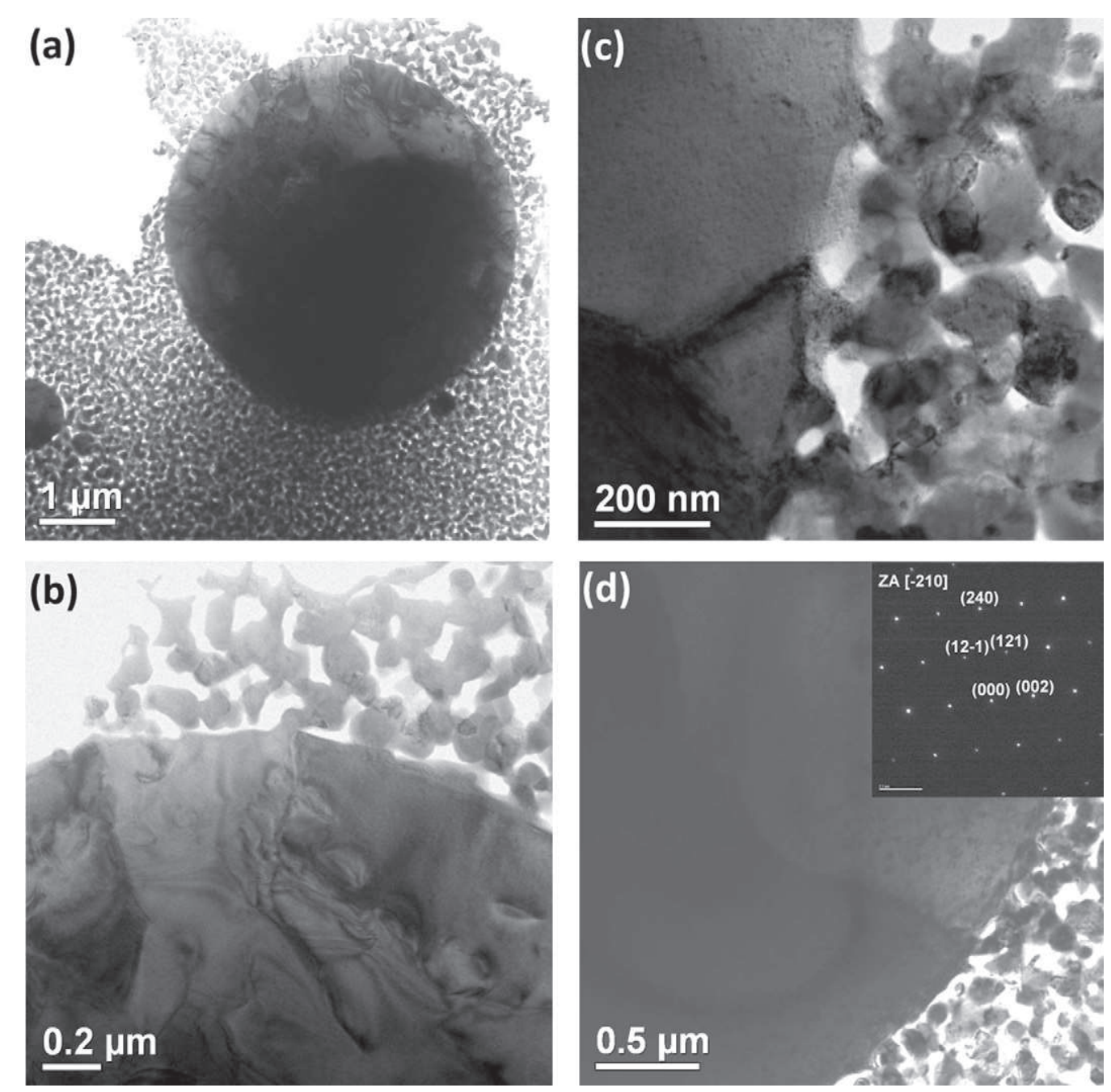

Fig. 8. TEM images showing the (a) nucleation and growth of the spherical cubic $\mathrm{Y}_{2} \mathrm{O}_{3}$ grains on account of the multiphase nanocrystalline matrix at $1000{ }^{\circ} \mathrm{C}$. (b) $\mathrm{Higher}$ magnification of (a) showing the vermicular structure of the matrix nanoparticles. (c) The interface-controlled growth of the spherical cubic grains at $1100{ }^{\circ} \mathrm{C}$. (d) Selected area diffraction pattern confirmed the cubic symmetry of the spherical $\mathrm{Y}_{2} \mathrm{O}_{3}$ grains.

compacts was preserved. However, significant grain growth to micrometer-size grains was observed at higher temperatures [16]. The microstructural evolution associated with the polymorphic phase transformation is the basis for the observed densification behavior of the multiphase nanoparticles and will be discussed below.

\section{Discussion}

The observed densification behavior of the two nanopowders can be explained by the metastable nature of the monoclinic polymorph. The monoclinic phase is a high pressure version of $\mathrm{Y}_{2} \mathrm{O}_{3}$, but can be retained in a metastable state at the atmospheric conditions when in the nanoparticle form. These aspects of polymorphism, especially in the $\mathrm{Y}_{2} \mathrm{O}_{3}$ nano-particles, were discussed in detail elsewhere [19,21,22]. Although both powders exhibited a close to nanocrystalline particle size (18-nm vs. $41-\mathrm{nm}$ ), the surface enthalpy of the monoclinic polymorph is significantly higher $\left(2.78 \mathrm{~J} \mathrm{~m}^{-2}\right)$ than that of the cubic phase $\left(1.66 \mathrm{~J} \mathrm{~m}^{-2}\right)$ [19]. Therefore, the highly active surfaces of the monoclinic nano-particles act as an efficient driving force for low-temperature sintering and neck formation. This type of high sinterability is well characterized in transition alumina ( $\gamma$-alumina) and lead to rapid formation of a rigid porous skeleton by surface diffusion at low temperatures [23]; the resultant vermicular structure leads to low-density sintered compacts. In this respect, consolidation of alumina nanoparticles by SPS showed enhanced densification of the $\alpha$-alumina compared to that of transition $\gamma$-alumina [24]. Surprisingly, dense $\alpha$-alumina was obtained at a considerably lower SPS temperature, albeit originally with a larger particle size. This behavior was related to $\gamma \rightarrow \alpha$ phase transformation during the SPS, which in turn led to the formation of the vermicular structure.

The theoretical densities of the cubic $(c)$ and monoclinic $(m)$ $\mathrm{Y}_{2} \mathrm{O}_{3}$ polymorphs are $5.030 \mathrm{~g} \mathrm{~cm}^{-3}$ and $5.468 \mathrm{~g} \mathrm{~cm}^{-3}$, respectively [19]. Consequently, the polymorphic $m \rightarrow c$ phase transformation is associated with $\sim 8 \%$ volume increase. Nevertheless, the DSC results indicated the polymorphic transformation temperature to be around $1000{ }^{\circ} \mathrm{C}$, where a rigid skeleton of $m \mathrm{Y}_{2} \mathrm{O}_{3}$ has been developed fairly well. On one hand, the kinetics of this interface-controlled polymorphic phase transformation is more sluggish compared to the SPS heating time scale, as evidenced by XRD analysis. On the other hand, the presence of the nanopores within the spherical particles is an evidence for a very rapid interface-controlled process (i.e. nano-pores were not annealed by diffusion). Consequently the change in the compact volume during the heating, due to the phase transformation, may be marginal. Similar effects were reported during densification of $\mathrm{Si}_{3} \mathrm{~N}_{4}$ with 

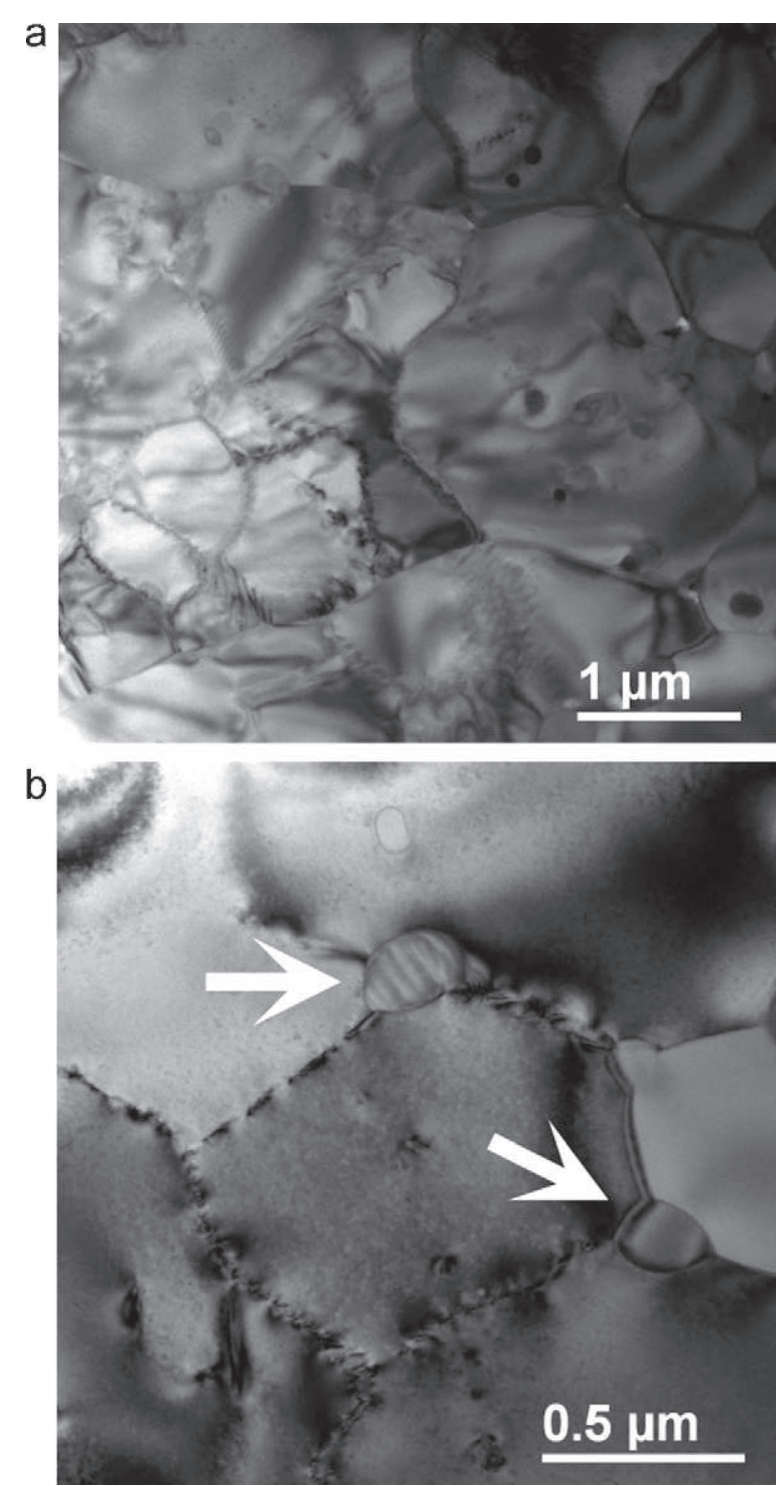

Fig. 9. TEM images showing the (a) micrometer-size cubic grains formed at $1500^{\circ} \mathrm{C}$. A few pores are visible along the grain boundaries. (b) Many sub-grain boundaries decorated with dislocation networks and nano-grains were present (arrowed).

metallic sintering additive by SPS [25], where significant shrinkage occurred by particle rearrangement and while a liquid phase was formed. However, minor shrinkage was observed when phase transformation and grain growth via solution-reprecipitation took place.

Based on the microstructure developed in the multiphase nanoparticle compacts, the following processes may be considered. First, the application of external pressure at room temperature enables particle sliding and rearrangement. The early and rapid densification stage ceases when reaching the maximal pressure applied. Second, highly reactive surfaces of the $m$ nanoparticles enable enhanced neck formation and growth by surface diffusion during the heating. The partially sintered $m$ nanoparticles form a rigid and porous skeleton with a vermicular structure which opposes further densification by particle sliding. At and above the polymorphic $m \rightarrow c$ phase transformation temperature, nucleation of the stable $c$ phase takes place, homogeneously throughout the porous skeleton (the homogeneous/heterogeneous nature of the nucleation event was not investigated here). Further growth of the cubic nuclei by this interfaced-controlled transformation results in spherical polycrystalline particles. Apparently, the $8 \%$ volume increase accompanied to the transformation, is not sufficient to overcome the volume constraints imposed on the growing spherical particles within the rigid porous matrix. Consequently, the elastic constraints may be reduced by the formation of dislocation networks and sub-grains, which, in turn, grow on the account of the $m+c$ nanoparticles, at their growing front. When the rapidly growing front of the spherical particle faces a large cavity of the vermicular structure, it may surpass it, due to insufficient time for diffusion, resulting in occluded nano-pores. At higher temperature, when the phase transformation is accomplished, particle sliding, dislocation creep, and grain growth may be responsible for the later stage densification close to full density.

Finally, the effect of the volume change during the polymorphic phase transformation to densification of the multiphase $\mathrm{Y}_{2} \mathrm{O}_{3}$ nanoparticles was negligible. Nevertheless, the metastable nature and the high surface activity of this polymorph were the major cause for the formation of the vermicular structure, which in turn, inhibited the densification during the heating by SPS. The interfacecontrolled character of the transformation led to the formation of very large cubic grains, responsible for the loss of nanometric character of the compact subjected to densification.

\section{Summary}

Spark plasma sintering of the multiphase monoclinic and cubic $\mathrm{Y}_{2} \mathrm{O}_{3}$ nanoparticles at $1000^{\circ} \mathrm{C}$ exhibited limited densification compared to the rapid densification of the cubic single-phase counterpart. XRD of the multiphase sintered compacts revealed that the polymorphic monoclinic to cubic phase transformation occurred during the SPS around $1000^{\circ} \mathrm{C}$, and was completed by reaching $1100^{\circ} \mathrm{C}$. The metastable monoclinic phase led to rapid neck formation during the heating which resulted in a vermicular nanometric matrix with open porosity network; this limited further densification of the multiphase nanopowder and ended in very low final densities. At SPS temperatures above the polymorphic transformation temperature, homogeneous nucleation of the spherical cubic $\mathrm{Y}_{2} \mathrm{O}_{3}$ grains was observed within the vermicular matrix. This interface controlled monoclinic to cubic phase transformation resulted in the loss of the nanocrystalline character of the compact. SPS of the multiphase nanoparticles at $1500^{\circ} \mathrm{C}$ showed similar densification behavior as the pure cubic $\mathrm{Y}_{2} \mathrm{O}_{3}$, resulting in a dense microstructure and coarse micrometer-size polyhedral shaped grains.

\section{Acknowledgments}

The financial support of the Israel Ministry of Science under contract \# 3-3429 is gratefully acknowledged. We thank Dr. Ori Yeheskel from NRC-Negev for supplying the MP nanopowder.

\section{References}

[1] S.-J.L. Kang, Sintering, Densification, Grain Growth \& Microstructure, Elsevier, Amsterdam, 2005

[2] J. Liu, D.P. DeLo, Metal. Mater. Trans. A 32 (2001) 3117-3124.

[3] C.L. Martin, D. Bouvard, S. Shima, J. Mech. Phys. Solids 51 (2003) 667-693.

[4] R. Chaim, R. Reshef, G. Liu, Z. Shen, Mater. Sci. Eng. A 528 (2010) 2936-2940.

[5] E. Artz, M.F. Ashby, K.E. Easterling, Metall. Trans. A 14A (1983) 211-221.

[6] R. Chaim, M. Margulis, Mater. Sci. Eng. A 407 (2005) 180-187.

[7] D.A. Porter, K.E. Easterling, M.Y. Sherif, Phase Transformations in Metals and Alloys, 3rd edition, CRC Press, Boca Raton, 2009.

[8] B. Li, X. Wang, L. Li, H. Zhou, X. Liu, X. Han, Y. Zhang, X. Qi, X. Deng, Mater. Chem. Phys. 83 (2004) 23-28.

[9] T. Takeuchi, M. Tabuchi, H. Kageyama, Y. Suyama, J. Am. Ceram. Soc. 82 (1999) 939-943.

[10] X. Deng, X. Wang, H. Wen, A. Kang, Z. Gui, L. Li, J. Am. Ceram. Soc. 89 (2006) 1059-1064.

[11] J. Liu, Z. Shen, M. Nygren, B. Su, T.W. Button, J. Am. Ceram. Soc. 89 (2006) 2689-2694.

[12] K-N.P. Kumar, K. Keizer, A.J. Burggraaf, T. Okubo, H. Nagamoto, S. Morooka, Nature 358 (1992) 48-51. 
[13] Y.I. Lee, J.-H. Lee, S.-H. Hong, D.-Y. Kim, Mater. Res. Bull. 38 (2003) 925-

[14] U. Anselmi-Tamburini, J.E. Garay, Z.A. Munir, Mater. Sci. Eng. A 407 (2005) 24-30.

[15] R. Marder, R. Chaim, C. Estournes, Mater. Sci. Eng. A 527 (2010) 1577-1585.

[16] R. Chaim, A. Shlayer, C. Estournes, J. Eur. Ceram. Soc. 29 (2009) 91-98.

[17] C. Suryanarayana, M. Grant Norton, X-ray Diffraction, A Practical Approach, Plenum Press, New York, 1998, pp. 223-236.

[18] I. Halevy, R. Carmon, M.L. Winterrose, O. Yeheskel, E. Tiferet, S. Ghose, J. Phys. Conf. Ser. 215 (2010) 012003.
[19] P. Zhang, A. Navrotsky, B. Guo, I. Kennedy, A.N. Clark, C. Lesher, Q. Liu, J. Phys. Chem. C 112 (2008) 932-938.

[20] R. Marder, R. Chaim, G. Chevallier, C. Estournes, J. Eur. Ceram. Soc. 31 (2011) 1057-1066.

[21] A. Camenzind, R. Strobel, S.E. Pratsinis, Chem. Phys. Lett. 415 (2005) 193-197.

[22] B. Guo, A. Harvey, S.H. Risbud, I.M. Kennedy, Phil. Mag. Lett. 86 (2006) 457-467.

[23] F.W. Dynys, J.W. Halloran, J. Am. Ceram. Soc. 65 (1982) 442-448.

[24] R.S. Mishra, S.H. Risbud, A.K. Mukherjee, J. Mater. Res. 13 (1998) 86-89.

[25] G.H. Peng, X.G. Li, M. Liang, Z.H. Liang, Q. Liu, W.L. Li, Scripta Mater. 61 (2009) $347-350$. 